Too close for comfort? The effect of embeddedness and competitive overlap on client relationship retention following an acquisition"

\author{
Michelle Rogan \\ michelle.rogan@insead.edu \\ INSEAD \\ Boulevard de Constance \\ 77305 Fontainebleau Cedex \\ FRANCE
}

November 2012

Forthcoming in Organization Science

\footnotetext{
* This research was funded in part by the Advanced Institute for Management Research, the European Social Research Council, and the INSEAD Alumni Fund. I am extremely grateful to my late thesis adviser Bjørn Løvås for his support in the earlier stages of this research. Matthew Bidwell, Julian Birkinshaw, Isabel FernandezMateo, Martin Gargiulo, Henrich Greve, Isin Guler, Morten Hansen, Quy Huy, Susan Lynch, Costas Markides, Louise Mors, Phanish Puranam, Dimo Ringov, Jasjit Singh, Olav Sorenson, Bart Vanneste, Andrew von Nordenflycht, Christoph Zott and seminar audiences at Harvard Business School, HEC Paris, INSEAD, London Business School, Rotman School of Management, Tilburg University, and the University of Michigan provided helpful comments.
} 


\title{
Too close for comfort? The effect of embeddedness and competitive overlap on client relationship retention following an acquisition
}

\begin{abstract}
Drawing on insights from network dynamics and exchange theory, I develop and test arguments for the retention or dissolution of exchange relationships. I exploit mergers and acquisitions among advertising firms as strategic actions that change the networks in which they and their clients are situated, and examine the consequences of these changes for their network relationships. Analysis of an archival, longitudinal dataset confirms that, in general, relational embeddedness reduces the likelihood of dissolution, and that increases in competitive overlap among clients increase dissolution likelihood. The results also provide evidence of a significant interaction effect between relational embeddedness and competitive overlap. For low to moderate increases in competitive overlap, embeddedness reduces dissolution likelihood. However, when the merger results in a high increase in competitive overlap, increasing embeddedness actually increases dissolution likelihood. Mechanisms to explain the findings are explored, including private information leakage fears and trust betrayal. The findings suggest that under certain conditions, relational embeddedness can reduce - rather than increase - relationship stability.
\end{abstract}


The idea that social structure shapes economic action is well established in organization theory (Granovetter 1985). A plethora of studies have investigated the origins of social structure and its effects on economic outcomes (e.g. Burt 1992, Coleman 1988, Gulati and Gargiulo 1999, Podolny 1994). In particular, scholars have devoted significant attention to identifying the factors that affect the formation of relations between firms. For example, both prior exchange (e.g. Beckman et al. 2004, Gulati 1995) and third-party referrals (e.g. Podolny 1994) have been shown to reduce uncertainty regarding potential partners and therefore to increase relationship formation. Furthermore, the tendency to exchange with known partners promotes stable networks of embedded relations (Gulati and Gargiulo 1999). Together these studies provide insight into the processes of relationship formation and the stability of exchange.

Yet, because previous research has focused on explaining the formation of relationships, theory explaining the dissolution of interorganizational relationships remains underdeveloped (cf. Baker et al. 1998, Broschak 2004). Studies of the "dark side" of relationships (e.g. Gargiulo and Benassi 1999, Soda and Usai 1999) indicate that inertia and lock-in arising from existing relationships can hinder firm adaptation (e.g. Singh and Mitchell 1996) and restrict the flow of novel information to the firm (Burt 1992, Hansen 1999), but they offer little insight into dissolution. Other studies have found that the greater a relationship's embeddedness, the less likely it is to dissolve, for example if firms have exchanged in the past (Polidoro et al. 2011) or if more relational attachments exist between the firms (Seabright et al. 1992). Finally, some studies point to firm or industry level factors such as changes in resource requirements (e.g. Seabright et al. 1992) and industry shocks (Gulati and Gargiulo 1999) that increase rates of dissolution. Taken together, these studies imply that over time a firm's existing networks will move towards greater stability unless an exogenous change disrupts the network of relationships, a conclusion that does not offer much traction for developing a theory of network evolution. Unless one assumes that existing relationships persist indefinitely, or that they are dissolved at random, further theory development is needed.

Recently, a few studies have begun to investigate the role of competitive frictions in relationship dissolution. For example, in Rowley and colleagues (2005) study of investment bank cliques, role similarity of clique members increased competitive frictions, making exit from the clique 
more likely. Similarly, Greve and colleagues (2010) found that whereas embeddedness reduced the likelihood of alliance dissolution, competitive frictions between alliance partners such as resource incompatibility or market overlap increased dissolution likelihood. The current study adds to this nascent stream of research by examining the implications of increases in competitive frictions among a firm's partners for relationship dissolution. It extends prior work in two key ways. First, it takes a network perspective and investigates the effect of changes in indirect competitive frictions within the exchange network rather than direct competition between a firm and its partner. Second, rather than assuming that embeddedness necessarily stabilizes exchange, the study explores how the effect of embeddedness on relationship stability changes when competitive frictions increase, providing insight into the conditions under which embedded relationships are likely to dissolve.

To develop arguments for the dissolution of relationships when competitive frictions increase, I draw on insights from network dynamics research (e.g. Ahuja et al. 2012, Koka et al. 2006, Powell et al. 2005, Shipilov et al. 2006) and exchange theory (e.g. Baker 1990, Cook et al. 1983, Emerson 1962). According to the network dynamics view, networks continually evolve as relationships are formed and dissolved. Scholars have therefore focused on identifying the mechanisms that determine patterns of affiliation among organizational actors in networks. These include forces that motivate the formation of embedded relationships, such as uncertainty reduction (e.g. Gulati 1995, Stark and Vedres 2006), as well as those that can hinder relationship formation, such as competition (e.g. Baker et al. 1998). In addition, studies of network dynamics suggest that the affiliation preferences of organizational actors may change, given changes in the overall network. For example, research has shown that the addition of indirect ties within an alliance network (ties to the focal firm's alliance partners' partners) affects patterns of relationship formation within the network (Gimeno 2004). Likewise, according to exchange theory, as networks evolve and the substitutability and complementarity of actors within them change, actors may be motivated to withdraw from exchange (Cook et al. 1983, Yamaguchi 1996).

To investigate the interplay of embeddedness and competitive frictions on relationship stability, I examine the effect of the addition of ties by a firm to its network via mergers and acquisitions on the evolution of its exchange network. A merger or acquisition is a strategic action that changes the 
merged firm's network, intentionally or unintentionally. It regularly involves joining the merging firms' sets of exchange relationships, altering the network of relationships in which they and their exchange partners are situated (e.g. Capron 1999, Madhavan et al. 1998). This affects the merging firms' networks in two specific ways. First, it creates an ownership tie between the merging firms, and second, it introduces new indirect ties among exchange partners in the merged firm's network of relationships. When these indirectly tied exchange partners are also competitors in their own industries, the potential for competitive friction among exchange partners, i.e. competitive overlap within the merged firm's network, increases. Observing the effect of increases in competitive overlap provides an opportunity to develop insights into when relationships are retained or dissolved and the role the firm's actions play in strengthening and destabilizing its network of relationships.

I test my arguments in the context of professional services, focusing on mergers and acquisitions among advertising firms. Professional service industries are particularly good settings for studying exchange relationships, and several researchers have applied a network perspective to the study of firms in these industries (e.g. Baum et al. 2005, Koza and Lewin 1999, McEvily et al. 2012, Shipilov 2006). In industries such as law, accounting, advertising, financial services and consulting, the quality of the service provided often cannot be verified ex ante. To reduce this uncertainty, clients (i.e. exchange partners) tend to use the same professional service provider repeatedly, and so relationships are often highly embedded, i.e. characterized by a long history of prior exchange (Baum et al. 2012, Eccles and Crane 1988, Uzzi and Gillespie 2002). In addition, competitive overlap-the degree to which a professional service firm's portfolio includes client firms that compete in their respective industries - varies significantly across client relationships. I examine the effects of changes in competitive overlap, relational embeddedness and their interaction, on the likelihood of client relationship dissolution. In contrast to the null hypothesis that more embedded relationships should be less likely to dissolve when competitive overlap increases or that there should be no effect, I argue that they should be more likely to dissolve due to the greater potential for trust betrayal and information leakage in embedded relationships. The arguments are tested using archival data on a longitudinal sample of advertising firm-client relationships. I find that while embeddedness decreases dissolution likelihood and increases in competitive overlap increase dissolution likelihood, when the 
post-merger increase in competitive overlap is high, embeddedness actually increases the likelihood of dissolution of a relationship. Furthermore, I show that this effect exists above and beyond the disruptions to the merging firms and their clients caused by the merger or acquisition.

This study extends research on the role competitive frictions play in exchange, and adds to a recent stream of studies that have begun to explore its effects on relationship dissolution (e.g. Greve et al. 2010, Rowley et al. 2005). The findings also have implications for research on embeddedness. In addition to the problems of embeddedness for limiting inflows of novel information and constraining firm behaviour (Burt 1992, Hansen 1999, Uzzi 1997), I argue that embeddedness increases the potential for malfeasance (Granovetter 1985) through trust betrayal and private information leakage. Consistent with this argument I find that although embeddedness generally slows the dissolution of relationships, it also increases the likelihood of dissolution when competitive frictions among a firm's exchange partners are high. Lastly, this study contributes to network dynamics research (e.g. Ahuja et al. 2012, Koka et al. 2006, Powell et al. 2005, Shipilov et al. 2006) by providing an explanation for when tensions internal to relationships lead to their dissolution and advancing the development of a more complete theory of network evolution.

\section{THEORY}

\section{Relational embeddedness}

In network dynamics research, the patterns of affiliation observed among firms are viewed as the result of the interplay of a set of forces that affect the likelihood of relationship formation. One force is the need to reduce uncertainty in exchange. Firms reduce uncertainty by engaging in repeated exchange with the same partners, i.e., increasing relational embeddedness (e.g. Beckman et al. 2004, Geertz 1978, Li and Rowley 2002, Uzzi 1997). Relational embeddedness offers benefits to exchange partners such as fine-grained information sharing (e.g. Larson 1992, Reagans and McEvily 2003), joint problem solving (e.g. McEvily and Marcus 2005), and cooperation and trust (e.g. Coleman 1988, 1994; Uzzi 1997). According to network scholars (Dore 1983, Granovetter 1985, Gulati 1995, Uzzi 1997), relationships become embedded over repeated interactions, which facilitate information sharing and trust development, further increasing the embeddedness of the relationship. Accordingly, 
studies of patterns of relationship dissolution have shown that the likelihood of relationship dissolution decreases over time (e.g. Baker et al. 1998, Levinthal and Fichman 1988, Seabright et al. 1992). In addition, exchange partners also tend to allocate more resources to their embedded relationships, creating an additional incentive for the partners to continue in the exchange. Finally, on average, embedded relationships are more valuable to firms (Dyer and Chu 2003, Gulati and Sytch 2007), and thus embeddedness increases the likelihood that partners will stay in the relationships.

Firms regularly undertake mergers and acquisitions when implementing growth strategies targeted at increasing the firm's customer base or expanding into new markets. These are often disruptive events for the exchange partners of the merging firms (Madhavan et al. 1998). Acquisitions may be associated with a temporary decline in the quality of services while management attention is diverted to integration activities (Buono and Bowditch 1989), and are sometimes followed by executive departures (e.g. Hambrick and Cannella 1993, Walsh 1988), which in turn may be associated with loss of customers (Broschak 2004, Somaya et al. 2008). The stability of any exchange relationship of the merged firm is likely to decrease given the many disruptions associated with acquisitions. Yet embedded relationships are more likely to weather temporary downturns during acquisition integration, given the inertia associated with repeat exchange (Levinthal and Fichman 1988) and the desire to preserve the valuable relationship that has developed between the exchange partner and the firm (Baker et al. 1998, Dyer and Chu, 2003, Gulati and Sytch 2007).

In professional services industries, embeddedness should decrease the likelihood of relationship dissolution post-acquisition. Studies of interorganizational relationships of professional services firms (e.g. Baker et al. 1998, Seabright et al. 1992) show that firms develop specialized procedures, processes, and knowledge over time, increasing the likelihood that their relationships continue. For example, in investment banking, clients prefer to exchange with the same bank because information flows with the bank are enhanced, and the bank is better able to respond to the client's needs (Eccles and Crane 1988). In the current study's context, an advertising firm in an embedded client relationship gains "deep knowledge of the client and product" and "a deep knowledge of the essence of the brand", thereby improving the firm's ability to serve its client (Gleason and Sloan 1997: 3-4), increasing the likelihood of continued exchange. Therefore, consistent with embeddedness research 
outside the mergers context, I expect embeddedness to decrease dissolution likelihood of client relationships following a merger of advertising firms.

Hypothesis 1: Following a merger of advertising firms, client relationships that have greater relational embeddedness are less likely to dissolve than less embedded relationships.

\section{Competitive overlap}

According to network dynamics arguments, firms' preferences for affiliation with others are also shaped by competition concerns. In general, competition is a destabilizing force for interorganizational relationships (Baker et al. 1998). Relationship formation is less likely when firms are direct competitors rather than complements (Chung et al. 2000, Gulati and Gargiulo 1999), and when relationships between competitors do form, they are less stable (Park and Russo 1996). Furthermore, and most relevant to the current study, competition concerns also extend to third party ties. As shown in Gimeno's (2004) study of the global airline industry's alliance networks, firms avoided relationships with potential partners if they also had co-specialized alliances with the firms' competitors.

Competitive overlap exists between two or more firms when they occupy the same space within an industry or a network, and the intensity of competition among these overlapped firms is a function of the number of similar firms (i.e. crowding) in the same space (Baum and Singh 1994, Hannan and Freeman 1989). In this study, I examine competitive overlap among a firm's exchange partners, in contrast to direct overlap between a firm and its partners examined in other recent studies (Greve et al. 2010, Polidoro et al. 2011). The level of competitive overlap for a firm's exchange partners may change as the firm adds and drops exchange relationships organically or when it acquires relationships via mergers and acquisitions, the focus of this study. As depicted in Figure 1, Client A of the Target and Client $\mathrm{C}$ of the Acquirer, who both compete in Industry 1, experience an increase in competitive overlap as a result of the merger, while Client B of the Acquirer, who competes in Industry 2, does not.

Insert Figure 1 about here 
Increases in competitive overlap can have at least three effects on merging firms' exchange partners. First, to the extent the resources provided by a firm are scarce, finite and heterogeneous in quality, competition for access to these resources can increase as more of an exchange partner's competitors are added to the firm's exchange network (Gimeno 2004). Allocation of resources is a concern for all exchange partners but it is exacerbated when exchange partners are direct competitors. In advertising services, using the same resources to serve competing clients constitutes a conflict of interest. Thus, as more competing clients enter the advertising firm's portfolio of relationships (i.e. as competitive overlap increases), the potential for resource allocation problems increases.

Second, exchange partners that operate in the same industry are likely to be substitutes rather than complements within the merged firm's network. The merged firm can more easily redeploy resources to a substitute exchange partner should the other partner withdraw from the exchange. It is less dependent on any single exchange partner (Bae and Gargiulo 2004, Emerson 1962), and thus the exchange partner's power relative to the merged firm decreases. For example, two clients operating in the same industry and targeting the same customer market are likely to have significant overlap in their advertising needs. The advertising firm's resources could be applied to one client relationship should the other client leave, and the threat of relationship termination by a client is less problematic for the advertising firm.

Third, increases in competitive overlap have implications for information flows within the exchange network. Relationships serve as information conduits (Ahuja 2000) that transmit "information and knowledge gathered from connected firms about their competitive intent, strategies and resources, even in the absence of any asset flows" (Gnywali and Madhavan 2001: 432). Furthermore, a firm's relationships provide it with access not only to the knowledge held by its partners but also to the knowledge held by its partners' partners (Gulati and Gargiulo 1999). When these partners are not competitors, information flows facilitate learning and innovation. In contrast, when they are competitors, information flows can be harmful to competing exchange partners. As the level of competitive overlap among exchange partners in the merged firm's network increases, possibilities for leakage of information from one exchange partner to its competitor via the merged firm also increase. 
Exchange theory (Emerson 1962) suggests at least two ways that an exchange partner can respond to concerns about competitive overlap: by decreasing the scope of the existing relationship (e.g. Oxley and Sampson 2004) or dissolving it completely (e.g. Kogut 1989, Park and Russo 1996). These two responses are not mutually exclusive, and relationship dissolution may be a staged process. For example, initially, the exchange partner may decrease the scope of its relationship to rebalance power in the relationship or to control continued sharing of sensitive information. Subsequently, it may dissolve its relationship after the sensitive information that had already been revealed to its service provider has been made public (e.g. through a new product launch) or when it finds an alternative exchange partner. Nevertheless, whether relationship dissolution is immediate or staged, both the theory and the evidence suggest that the likelihood of relationship dissolution should increase due to increased competitive overlap following the merger.

Hypothesis 2: Following a merger of advertising firms, the greater the competitive overlap increase for a given client, the more likely the client relationship is to dissolve.

\section{Embeddedness, competitive overlap and relationship dissolution}

As described in the first two hypotheses, both embeddedness and competition are factors that may affect the continuity of exchange relationships. Embeddedness, which reduces exchange uncertainty, predicts continued relationships with past partners, and thus relationship stability. Competition predicts avoidance of rivals as partners, and thus the dissolution of relationships. Given these two factors, should embeddedness increase or decrease the likelihood of dissolution when competitive overlap increases?

On first consideration, it would seem that the more embedded a relationship is, the less likely it should be to dissolve as competitive overlap increases. As described previously, competitive overlap impacts exchange partners by increasing their concerns over resource allocation, decreasing their relative power in exchange and increasing the potential for information leakage to competitors. Yet prior research has shown that firms tend to allocate a greater share of resources to their embedded partners (Sorenson and Waguespack 2006), and therefore the more embedded the relationship, the lower the resource allocation concern would be, or at least it would be the same. Firms also are less likely to exercise their power in embedded relationships because the use of power can damage the 
cooperative nature of the relationship, diminishing its value-generating potential (Piskorski and Casciaro 2006). Thus, the merged firm would be unlikely to take advantage of the shift in power arising from the competitive overlap increase with its embedded partners. Furthermore, despite the increased potential for information leakage due to competitive overlap, norms of trust should reassure embedded partners that the merged firm would take actions to ensure that their information is not leaked. For example, merging firms could erect "Chinese walls," formal internal procedures that restrict the flow of information between two or more groups. Lastly, inertia based on specialized investments in the relationships could also prevent relationship dissolution despite increases in competitive overlap.

Nevertheless, such arguments may be erroneous. They overlook two mechanisms - the potential for private information leakage and trust betrayal - that decrease the stability of embedded relationships when competitive overlap is high. First, not only the volume but also the sensitivity and privacy of information shared increases as a relationship becomes more embedded (Uzzi 1999, Uzzi and Lancaster 2004). Thus, although resource allocation concerns and power shift concerns are either lower or no different for embedded partners, their information leakage concerns are greater. Studies of advertising firms indicate that initially, clients withhold sensitive marketing information from their advertising firm (Hotz et al. 1982, Flandin et al. 1992). However, after repeated exchanges with the same advertising firm, they begin to share private information about product performance, market conditions, and market characteristics necessary for the production of effective advertising (Comanor et al. 1981, Helgesen 1994, Sutherland et al. 2004), which increases the client's vulnerability to information leakage. As argued in Hypothesis 2, the greater the increase in competitive overlap postmerger, the greater the possibilities for leakage of information from one exchange partner to its competitor via the merged firm. When this information is private, leakage can be highly detrimental to the exchange partner.

Moreover, the arguments may over-estimate the effectiveness of trust for preventing dissolution. While trust generally improves the likelihood of relationship continuity, the decision to merge with a firm that serves the competitors of an existing exchange partner could be perceived as a violation of the norms governing behavior in embedded exchange (Gulati and Sytch 2007, Gundlach 
and Cadotte 1994). According to McEvily, Perrone and Zaheer (2003: 99), trust operates as a "rule of thumb" rather than something fixed. Organizational actors periodically process information about their exchange partners to assess the fragility of trust, how they should interpret contradictory behaviors, and if they should increase their vulnerability in exchange. An exchange partner may interpret the merger and competitive overlap increase as a betrayal of the trust it placed in the merged firm. The exchange partner's inferences about the future behavior of the merged firm are likely to become negative, and it is less willing to expose itself to further vulnerability (Dirks et al. 2009). As Granovetter describes (1985: 491): “...While social relations may indeed often be a necessary condition for trust and trustworthy behaviour, they are not sufficient to guarantee these and may even provide occasion and means for malfeasance and conflict on a scale larger than in their absence." Thus, the greater the trust, the greater the potential for malfeasance, and therefore the greater the perceived violation of that trust. Rather then prevent dissolution, trust associated with embedded relationships may be ineffective at best, in which case concerns about private information leakage would prevail. At worst, it may increase the likelihood of dissolution due to feelings of betrayal.

To be sure, the advertising firm could erect Chinese walls to prevent information leakage. However, despite the reliance of many firms on Chinese walls, researchers have argued that they are “...flimsy safeguard(s) against defection from the relationship or access to unique resources” (Uzzi and Gillespie 2002: 599, Hayward and Boeker 1998), and even when they are effective, a firm's capacity for accommodating competing exchange partners is necessarily limited by its size. It is also possible that the exchange partner would respond by threatening to sanction the behavior of merged firm for example by filing a lawsuit against the advertising firm for leaking confidential information. However, information leakage cannot be observed until damage is incurred, and even when that damage is clearly related to information leakage, the exchange partner will find it difficult to prove it was the fault of their service firm (Asker and Ljungqvist 2010). Moreover, the need to exact sanctions reduces the value that the exchange partner previously gained from its relationship with the merged firm. Trust provides a means of reducing the costs of contracting (Dyer and Chu 2003). If the exchange partner must resort to sanctions, this is a clear indicator that trust has been lost. In experimental studies of trust, researchers have found that the use of sanctions undermined cooperation 
when trust was initially high (Mulder et al. 2006). Because the benefits of trust in the relationship are diminished, the switching costs for the partners decrease significantly; and the likelihood that the exchange partner will exit the relationship increases.

The above arguments assume that competitive overlap is problematic for exchange partners. Yet, it is possible that competitive overlap generates benefits, for example, mutual forbearance via multimarket contact (Bernheim and Whinston 1990, Gimeno and Woo 1996), positive information externalities (Katz and Shapiro 1985, 1986), or specialization benefits (Romer 1987). Nevertheless, I maintain that even allowing for the existence of potential benefits, on average embedded exchange partners will react negatively to increases in competitive overlap following the merger of service firms. First, managers in these firms may not recognize these benefits, or they may underestimate the benefits of coordination with competitors (Gimeno 2002). Indeed, multi-market contact between competitors often arises by chance rather than through managerial choice (Greve 2006, Korn and Baum 1999). Second, while in theory positive information externalities could exist, the actual evidence of these is limited (e.g. Breschi and Lissoni 2001, Liebowitz and Margolis 1994). Finally, specialization benefits are less likely to accrue to embedded partners than to arm's-length partners because a service firm's expertise in an industry sector arises from experience with its incumbent partners, and then spills over to its new ones. For these reasons, I posit that managers will react more strongly to information leakage fears and trust betrayal than to the relatively obscure benefits associated with competitive overlap. Formally,

Hypothesis 3: Following a merger of advertising firms, the positive effect of a competitive overlap increase on the likelihood of relationship dissolution (Hypothesis 2) increases with the embeddedness of the relationship.

\section{METHODS}

\section{Empirical setting}

I test these hypotheses on a longitudinal sample of client relationships of advertising firms generated from archival data. Advertising firms work with their clients to analyze the client's marketing problem, find advertising solutions that improve the marketing process, devise a creative approach for the advertising campaign and finally implement the campaign, either as independent 
agencies or multi-agency firms within the same holding company. While the average length of a relationship is approximately five years (AAAA 1997, Broschak, 2004), client relationships range from arm's-length relationships of only a few months' duration to highly embedded relationships spanning many decades, such as J. Walter Thompson's more than 100-year relationship with the household products company Unilever. Estimates of annual turnover of client account relationships are difficult to obtain. However, prior research into US advertising firms shows that on average they lose 20 percent of their client relationships each year (Broschak 2004).

To observe the impact of a change in network structure on advertising firms' existing relationships with clients, I exploit mergers and acquisitions among advertising firms as changes that alter firm networks and thereby may increase the level of competitive overlap for clients of the merged firm. Advertising firms regularly use mergers and acquisitions as a means of implementing growth strategies, i.e. to gain new clients or new services to offer existing clients (e.g. Ducoffe and Smith 1994). These mergers provide a good context for studying the impact of embeddedness and competitive overlap on the dissolution of relationships. First, the post-acquisition loss of relationships is not usually intentional, unlike the planned shedding of other firm resources (e.g. redundant back office functions). Second, there is sufficient variation in the change in the level of competitive overlap experienced by clients to conduct the analysis on a sample of reasonable size. Third, all of the merged firm's clients in the same industry simultaneously experience the related change in competitive overlap and increased risk of dissolution. However, because the choice to acquire is not exogenous, I correct for selection bias in the analyses, controlling for the probability of being in an acquisition. Finally, advertising firms regularly report wins and losses of client relationships and the start and end of a client account can be determined accurately for most relationships.

\section{Sample}

To conduct the analysis, I collected a longitudinal sample of client relationships of advertising firms in North America and Europe that were involved in a completed acquisition in the year 2000 in the US Standard Industry Classification (SIC) code 7311, "Advertising agencies." I gathered data on the population of acquisitions of US-based target firms made by North American or European acquiring firms in 2000 in SIC code 7311 from SDC Platinum ${ }^{\mathrm{TM}}$. I then matched the acquiring firms 
and target firms to the correct advertising agencies listed in the Standard Directory of Advertising Agencies (also known as The Advertising Redbooks ${ }^{\mathrm{TM}}$ ). A complete advertising agency record in The Redbooks includes information on firm location, size, annual billings, executive names/functions and client relationships, and is updated annually. Acquisitions were eliminated if the acquiring and target firms involved reported only basic information or omitted client names. Ten acquisitions from a population of 36 were selected based on availability of advertising firm data in The Redbooks. T-tests showed no significant differences in means and standard deviations between the population and the sample of acquisitions for date announced, date effective, percent shares acquired or estimated integration level. Of the ten acquisitions in the sample, four were mergers between independent agencies and six were acquisitions of independent agencies by multi-agency firms. Accurately measuring competitive overlap requires data on the client relationships of all agencies in the merging advertising firms. Therefore for the six multi-agency acquisitions, all agencies within each advertising multi-agency firm were included, resulting in a total of 108 advertising agencies in the main sample. To construct the dyad level sample, (i.e. agency-client relationships), I recorded the client names listed by each of the agencies in the sample from The Redbooks. Across the ten acquisitions, 3,256 pre-acquisition agency-client relationships were constructed based on the lists of clients reported by each of the 108 agencies one year prior to its acquisition. ${ }^{1}$

The main sample included 1,322 unique client firms. Client data were collected from a set of databases published by Bureau Van Dyjk (AMADEUS, OSIRIS, and ORBIS), which together provided the best available coverage for the client firms in the sample. When client data were not available in these databases, data were obtained from Dun \& Bradstreet. Client matches between the databases were made by matching the name of the client, the geographic location of the client or the agency listing the client and, if given, the description of the account in The Redbooks. Of the 3,256 relationships in the sample, client data were identified for 2,574 relationships. The final sample with complete data for all independent variables included 2,167 relationships. T-tests for differences in

\footnotetext{
${ }^{1}$ A possible concern involves the small number of mergers in the sample. However, the variables of interest are all defined at the dyadic level, and acquisition fixed effects are included in the models. Therefore the models estimate the likelihood of relationship dissolution for a set of relationships within a particular merger, and the number of relationships is the relevant sample size for the analyses.
} 
means and standard deviations for the full and final samples showed a bias toward client relationships held by larger agencies (employees), older agencies, and agencies with higher annual billings. This was not surprising or unusual, as the availability of archival data for newer and smaller firms tends to be poor. I tracked the survival of these relationships for three years post-acquisition (2000 to 2003) in The Redbooks or until the relationship failed, resulting in a final sample of 5,899 dyad-years used in the analyses.

Because the main sample included only dyads of advertising firms experiencing a merger or acquisition, the results were subject to selection bias (Heckman 1979). Therefore, I also constructed a control sample by randomly selecting 220 firms from the population of advertising firms in the United States or Europe in the year 2000 not involved in an acquisition two years before and after (1998 to 2002) from The Redbooks, mirroring the selection criteria for the main sample. Including the other agencies in multi-agency firms increased the potential sample to 405 firms. I dropped firms if further research indicated they were not classified in SIC code 7311 or were in-house agencies, and if client data were not available. The control sample included 174 advertising firms and 1,415 client firms in 2,692 client relationships with complete data for 1,466 relationships. T-tests for difference in means and standard deviations for the full and final samples showed that relationships in the control sample were longer duration, and held by older agencies and agencies with higher annual billings. I tracked the survival of these relationships for three years (2000-2003) in The Redbooks, resulting in a final control sample of 3,638 dyad-years.

\section{Dependent and independent variables}

The dependent variable is a dichotomous variable set to one if the client relationship dissolved in that year. A relationship is coded as dissolved the first year the advertising firm no longer lists the client account in its Redbooks record. If a relationship did not dissolve in the observation period (2000-2003) or if data were not available, the relationship was considered censored.

The main explanatory variables were relational embeddedness, difference in competitive overlap, and their interaction. Prior research indicates that embeddedness increases with the duration of a relationship (Blau 1964, Capaldo 2007, Gulati 1995, Seabright et al. 1992, Uzzi 1999, Uzzi and Gillespie 2002). Consistent with these studies, I used relationship duration as a measure of relational 
embeddedness. In the advertising industry, a client selects an advertising firm to develop its advertising campaign for a given project or a specific duration. At the end of the project, the client then decides if it will extend the work for a further year or if it will put the account up for review. Therefore the duration of a relationship represents a series of repeated decisions by the client to reengage the advertising firm (Farrelly and Quester 2003), consistent with prior definitions of relational embeddedness. Of course, relationship duration could also be capturing other qualities of the relationship, such as match quality or inertia. However, it is more likely that long-term relationships are embedded, given the high need for information sharing, joint problem solving and trust for the delivery of effective advertising (e.g. Sutherland et al. 2004). For example, the chief executive of a consumer products company described the fifty-year-long relationship to its advertising firm: "If you understand the brand, even name and launch the products, market the campaign - as had happened with both Brand A and Brand B - then you are working so closely with the clients that it is more of a partnership than anything else" (White 2007: 14).

To gather relationship duration data, I consulted archives of The Redbooks for each year dating back to 1980 or the next earliest available year in which the advertising agency listed client information and coded the start year for the relationship as the first year in which the agency listed the client in its Redbooks record. Relationship duration is the length of the relationship in years from its start year to 2000, the year of the acquisition, or the duration as of the year 2000 for observations in the control sample. For the relationships for which I was unable to determine the start year (21 percent in the main sample, 16 percent in the control sample), I set the start year as the first year in which data were available, and a variable - relationship duration truncation — was coded as 1 and included as a control variable in the analyses (Cox and Oakes 1984).

To construct the difference in competitive overlap for a given client relationship, I used a timevarying measure of the change in the number of client accounts with the same primary (four-digit) US SIC code in each year in the advertising firm's portfolio. The difference in competitive overlap is defined as the count of clients in the same SIC in the current year minus the count of clients in the same SIC in the previous year. The baseline for the first year is the count of clients in the acquirer and target separately, and for each subsequent year the baseline is the prior year's count for the merged 
firm. The measure was updated annually to take into account the addition or loss of clients in each year. Thus the differences in competitive overlap in the main sample reflect either the addition of relationships due to the merger in 2000 , or the organic formation or dissolution of client relationships in the following years. For the non-merger control sample, the differences reflect only organic formations or dissolutions. Although a precedent exists for using four-digit SIC code as an overlap measure (e.g. Echols and Tsai 2005, Oxley and Sampson 2004, Park and Russo 1996), to ensure it is good indicator of competitive overlap, I constructed a more fine-grained measure that incorporated size and location data with the SIC code data for client relationships in the industry sector, Chemicals and Allied Products. The correlation between the SIC-only competitive overlap measure and the measure incorporating size and region overlap is 0.88 (significant at 0.05 ), indicating that the SIC code measure is valid. In the analyses, I use a lagged measure of competitive overlap, so that the change in competitive overlap in the current year predicts client relationship dissolution in the following year. I created an interaction term of relationship duration at acquisition and difference in competitive overlap, centering each of the variables before generating their product term (Aiken and West 1999). Finally, because client firms may react differently to the same change in competitive overlap depending on their baseline level of competitive overlap, the count of overlaps in the year prior to the acquisition (or in 1999 for the control sample) was included as a separate variable for each relationship.

\section{Control variables}

Although the main focus of this paper is relational embeddedness, firms also reduce uncertainty by exchanging with their partner's partners, i.e. structurally embedding their relationships. Structural embeddedness describes the proportion of indirect ties among a firm's contacts (e.g. Gulati 1998). An advertising firm's contacts include both clients and other advertising agencies that are part of the same advertising holding company. When a client has a tie to another agency in the same holding company, there is an indirect tie between the agency and the client. Likewise, an indirect tie exists if the agency has a tie to another subsidiary within the same client firm. Following Rowley, Behrens and Krackhardt (2000), I measured structural embeddedness as the count of indirect ties divided by the total number of possible ties, i.e. ego network density, and updated the measure annually. 
Other dyad level controls include the agency's dependence on the client measured as the proportion of accounts an agency has with the same client (natural log). Large clients have been found to be less likely to dissolve their relationships with advertising firms (Baker et al. 1998), therefore, I controlled for the size of the client in each dyad by including an indicator set to 1 if a client firm was listed in the Fortune Global 500 in that year. ${ }^{2}$ The strategic importance of advertising services to the client could also affect its propensity to dissolve the relationship when competitive overlap increases. A control for the average advertising spend in the client's main industry as defined by 4-digit SIC code (natural $\log$ ) is included. Controls for the count of the client's industry segments and the annual change in the count are included as clients are more likely to drop and add exchange relationships when entering or exiting industry segments.

Exchange theory suggests that when alternatives to the merged firm are not available, exchange partners will be unlikely to dissolve their relationships with the merged firm (Emerson 1962). Therefore, I include a measure of the count of alternative advertising agencies in the same city as the advertising agency for each city and year in the observation period, as listed in the Redbooks (natural $\log )$

Several agency control variables are included in the models. The count of accounts held and lost by the agency by the agency each year control for unobserved agency level factors causing account losses and also address in part the non-independence of dissolutions in the sample. Advertising firms are likely to vary in their historical capability for accommodating competitive overlap among clients. I constructed an agency overlap capability measure by summing the durations of the relationships with its clients in each SIC code and subtracting the longest duration. Two overlap capability measures are included as controls: the overlap capability by SIC code and the agency's average overlap capability across all SIC codes. The count of agencies in the advertising parent firm

\footnotetext{
${ }^{2}$ Client revenue data were available for only 30 percent of the observations. Therefore, to capture client size effects, I matched client firms by name into a database of Fortune Global 500 firms from 2000 to 2003. As a robustness check of the dummy measure, I compared the mean revenue for those client firms listed in the Fortune Global 500 and those that were not for sub-sample for which revenue data were available. The mean revenue for non-Fortune Global 500 firms was approximately 4 billion USD and the mean for those firms listed in the Fortune Global 500 was approximately 12 billion USD. Although not as accurate a measure as actual revenue data, it does allow me to effectively separate large multinationals from local/regional client firms in the sample.
} 
and the count of employees in the agency (natural log) are also included as larger ad firms should be better able to accommodate increases in competitive overlap. Executive departures occur regularly post-acquisition (e.g. Hambrick and Cannella 1993, Krug and Aguilera 2005), and could lead to the loss of client relationships that executives have maintained (Broschak, 2004). A measure of the proportion of agency executives leaving the agency annually is included in all models. Higher quality advertising firms should be less likely to lose relationships post acquisition. I gathered data on the number of CLIO awards for advertising, design, and interactive, that each ad firm won in the five years prior to the acquisition (1995-1999) as a proxy for the quality of its creative work (Von Nordenflycht 2007). A dichotomous variable, award winning firm, set to 1 if an advertising firm won one or more CLIO awards, was included in the analyses. Other controls included a dummy variable, target, to control for whose client relationship, the target agency's or acquiring agency's, was lost post-acquisition and agency age at acquisition (natural log) to control for the possibility that clients may be more likely to sever ties with older agencies.

\section{Analysis}

For the main analysis, I used event history analysis with a discrete time hazard model. Although client relationship dissolutions were reported annually, in reality they could occur at any point in the year. Thus, the discrete time hazard model with the complementary log-log link function, which accounts for both the discrete nature of the data as well as the continuous nature of the actual dissolutions, was the best choice for the analysis (Allison 1982, 1984). Because there are multiple observations for each advertising agency, the data violate the assumption of independence in regression analysis, which can bias the standard errors. To address non-independence of observations, all models are estimated using robust standard errors clustered by the advertising parent firm-client parent firm dyad. ${ }^{3}$

An additional concern is that the main sample includes only observations of post-merger dyads. To address this concern, I controlled for the likelihood of being in a merger using Lee's (1983)

\footnotetext{
${ }^{3}$ Results also are consistent using robust clustering by advertising agencies or clustering by acquisition. An alternative approach to addressing non-independence, I implemented a two-way random effects model (Krackhardt 1987 1988, Rabe-Hesketh and Skrondal 2008) by agencies and client industry effects, which also produced consistent results.
} 
generalization of Heckman's (1979) two-stage estimator to estimate a selectivity model. All 3,633 client relationships (9,537 dyad-years) in the main sample and control sample were used to estimate a logit model in which the likelihood of experiencing an acquisition was the dependent variable. Proper identification of a selection model requires an instrumental variable that affects the likelihood of experiencing an acquisition, but does not directly affect the likelihood of client relationship dissolution (Greene 1997: 288). Prior research has found that public ownership of a firm is positively related to the likelihood of being involved in an acquisition, both as an acquirer or target (Pagano et al. 1996, 1998). At the same time, whether a firm is publicly or privately owned does not have a direct effect on its ability to retain clients. A dichotomous variable, public, set to 1 if a firm was publicly owned (including subsidiaries of publicly traded firms), was included as an instrumental variable. Public ownership is highly significant and positively related to being in an acquisition but it does not significantly affect the likelihood of relationship dissolution. From the first stage model, I estimated the inverse Mills ratio, the probability of a firm experiencing an acquisition, and included this selection correction in the main analysis.

Although the influence of unobserved heterogeneity cannot be ruled out entirely, I took a number of steps to address it. First, as noted above, all models include a correction for selection into acquisition as some unobserved factors that drive acquisition may also affect relationship dissolution post-acquisition. Second, the models are estimated including either acquisition fixed effects, which provide a conservative control for acquisition heterogeneity including, for example, the status of the acquiring firm, the percentage of shares acquired, or the integration level post acquisition; or agency fixed effects to eliminate unobservable time-invariant factors from the models. Third, client industry characteristics may also affect the relationship between the explanatory variables and outcome. Therefore the full models also include client industry fixed effects (two-digit SIC code).

\section{RESULTS}

Descriptive data for the main sample are given in Table 1, and correlations are reported in Table 2. On average 16 percent of the relationships dissolved each year in the observation period. The average duration of relationships was 4.19 years. The average increase in competitive overlap for all 
dyad-years was 0.12 overlaps. Seventeen percent of relationships experienced an increase in competitive overlap in the first period post-merger and among these relationships the average increase was 3.2 overlaps.

Table 3 reports the results for the main analyses. Model 1 tests hypotheses 1 and 2. As hypothesized, the effect of relational embeddedness on the likelihood of client relationship dissolution is negative and significant $(\mathrm{p}<0.01)$. The effect of the difference in competitive overlap is not significant. Model 2 tests the third hypothesis that the positive effect of a competitive overlap increase on the likelihood of relationship dissolution increases with the embeddedness of the relationship. The interaction term is positive and significant $(\mathrm{p}<0.05)$, indicating that clients react to competitive overlap differently depending on their level of relational embeddedness. Model 3 includes fixed effects for each advertising agency, and Model 4 adds fixed effects for each client industry sector defined by two-digit SIC code. In both fixed effects models, the main explanatory variables remain significantly related to relationship dissolution, and the model fit improves significantly (comparison models are the same model estimated without the fixed effects). Furthermore, in the fixed effects models, the difference in competitive overlap is positive and significant $(\mathrm{p}<0.05$ in Model 3 and $\mathrm{p}<0.001$ in Model 4). (Main effects were centered before creating the interaction term, allowing for an interpretation of the constituent effects as well as the interaction term). In all models, the effects of the control variables are in the expected directions, and the selection correction is not significant, indicating that selectivity effects are weak. In summary, controlling for agency fixed effects, client industry fixed effects and the likelihood of being in an acquisition, the hypotheses are supported.

\section{Insert Tables 1, 2 and 3 About Here}

\section{Robustness checks}

Estimating the model using the natural log transformation or square root transformation of the difference in competitive overlap produces consistent results. Excluding observations for which the difference in competitive overlap is extreme (greater than 3 or less than -3 ) also generates results consistent with those reported. Estimating the models using the proportional change in competitive overlap defined as the difference in competitive overlap divided by the baseline count of overlaps in 
the previous year reduces the model fit. No support for curvilinear effects of the difference in competitive overlap was found. Likewise, estimating the model using the natural log transformation of relationship duration at acquisition and also dropping outliers (duration greater than six years) produces consistent results. Finally, a test for a curvilinear effect of relational embeddedness did not yield significant results. The lack of a curvilinear effect counters match quality as an alternative explanation for retention, in which case a pattern of dissolution likelihood consistent with the 'liability of adolescence’ described by Levinthal and Fichman (1988) would have been expected.

\section{Interpretation}

Although the coefficients and their significance levels for the explanatory variables in the logistic models indicate support for the hypotheses, a full interpretation requires a graphical examination of these effects (Hoetker 2007, Petersen 1985). Figure 2 depicts the probabilities of relationship dissolution based on the agency and client industry fixed effects model in Model 4 in Table 3 holding all variables at their mean except for relational embeddedness, the difference in competitive overlap and their interaction. The graph illustrates that embeddedness decreases relationship dissolution, an increase in competitive overlap increases relationship dissolution, and the negative effect of embeddedness on dissolution decreases as competitive overlap increases. For example, a one standard deviation increase in the level of embeddedness reduces the probability of dissolution by 16 percent when the difference in competitive overlap is at its mean and by 8 percent when the difference in competitive overlap is one standard deviation above the mean. Furthermore, at high levels of competitive overlap difference, increasing embeddedness actually increases the probability of relationship dissolution. Specifically, when the competitive overlap difference is above 4.21 overlaps (calculated from the conditional probabilities), increasing embeddedness actually increases the probability of dissolution.

Insert Figure 2 About Here

\section{Further analysis}

As illustrated in Figure 2, advertising firms are able to accommodate embedded clients with competitive overlap up to a point, beyond which the likelihood of dissolution increases with 
embeddedness. One possible explanation for this finding is that the advertising firm may keep competing clients separated in different agencies within the same advertising parent firm, a form of Chinese wall. If this explanation is correct, the advertising firm's ability to accommodate competitive overlap and thus the tolerance of embedded clients for competitive overlap should vary with the number of agencies in the advertising firm. Reestimation of the models, including the three-way interaction of relational embeddedness, difference in competitive overlap and the count of agencies in the advertising firm, provides support for this explanation. (Tables of results are available from the author upon request.) As shown in Figure 3, the inflection point for the effect of embeddedness on relationship dissolution is lowest (2.51 competitive overlaps) when the count of agencies in the advertising firm is one standard deviation below the mean. At the mean, the inflection point increases to 4.57 , and at one standard deviation above the mean, it is 16.81 (outside the range shown on the graph). The pattern of results suggests that smaller advertising firms are less able to effectively implement Chinese walls, and therefore the level of competitive overlap increase at which embeddedness increases dissolution likelihood is much lower than for large advertising firms. This pattern contributes to an information leakage mechanism, for which one would expect the inflection point to vary with the count of agencies in the advertising firm, a point discussed further below. It also is less consistent with inertia as an alternative explanation whereby an increase in competitive overlap triggers a re-evaluation of otherwise inert relationships and subsequently the dissolution of some of these. However, in this case, one would expect the inflection point to be lower and not to vary with the number of agencies in the advertising firm.

Insert Figure 3 About Here

\section{DISCUSSION AND CONCLUSION}

One shortcoming of previous network research has been the relative absence of theory to explain the dissolution of relationships. In this study, I have drawn upon insights from network dynamics research and exchange theory, which, combined with prior embeddedness arguments, provide a starting point for developing arguments for the dissolution of exchange relationships when competitive frictions among exchange partners increase. I exploited mergers or acquisitions among 
advertising firms as events that altered the networks in which the merging firms' exchange partners were situated to examine the effect of a change in competitive overlap on the dissolution or retention of exchange relationships. The analysis of a set of client relationships of advertising firms provides support for the main contention of the paper-the factors that provide stability in embedded relationships can become bases for their future instability as the network in which they are situated evolves.

Consistent with prior research, this study demonstrates that relational embeddedness increases stability. This stability is due in part to the information exchange and trust inherent to the process of embedding relationships. The study also provided evidence of a weak positive effect of increases in competitive overlap on dissolution likelihood consistent with prior studies showing that competition is a destabilizing force on exchange (Baker et al. 1998, Greve et al. 2010, Park and Russo 1996). The weak effect may reflect the specialization and coordination benefits of competitive overlap in part cancelling the resource allocation, power shift and information leakage problems associated with competitive overlap.

The main finding of the study is a novel one. In contrast to the stability normally associated with embedded relationships, I find that the negative effect of relational embeddedness on relationship dissolution decreases as competitive overlap increases, and furthermore that relational embeddedness actually increases dissolution likelihood when post-acquisition competitive overlap increases are high. As noted in the theory, at least two mechanisms may lead to this outcome. First, the sensitivity and privacy of information shared increases with embeddedness, and thus embedded clients may fear leakage of this information to competitors. Second, embedded clients may view the increase in competitive overlap as a betrayal of trust and may choose to sever their ties to the advertising firm.

Although the data do not allow direct observation of these mechanisms, the results of the further analysis provide insight. Advertising firms often use Chinese walls to limit flows of information from one client to a competing client in the same portfolio. According to an information leakage argument, dissolution likelihood should increase with embeddedness if the advertising firm cannot effectively implement Chinese walls. Supporting this argument, in the further analysis the point at which the effect of increasing embeddedness on dissolution becomes positive varied with the 
capacity of the advertising firm for Chinese walls. Thus the evidence appears to be consistent with private information leakage fear as an explanation for relationship dissolution when both competitive overlap and embeddedness are high. However, it would be incorrect to conclude that the trust betrayal mechanism is not operating. Trust betrayal and information leakage fears are closely connected. A client executive explained, "It's very important that we trust that the information we give the [advertising] agency is private. They know where we are going to launch and when. That's important - if that's violated, then we're done with the agency" (Harris and Taylor 2003: 350). The behavior of advertising firms and clients in this study is perhaps more indicative of trust as a mixed-mode social judgment (McEvily 2011). The relatively high inflection point of competitive overlap at which embeddedness increases rather than decreases dissolution suggests that clients' trust in their agencies is a hybrid form of calculative and relational trust as described by McEvily (2011: 1273) rather than a pure form of either. Qualitative evidence supports this conceptualization. Describing how his advertising firm dealt with competitive overlap (i.e. conflict), a client executive explained, "The agencies remain separate. ...We would stay with our agency if we felt that they were preventing conflict. Personal trust based in relationships with the folks at the agency that I have been working with [is important]. I have never been concerned that they could not find a way to manage client conflict." (personal interview 2003). Trust can be partly relational, based on personal ties, and partly calculative, based on the advertising firm's capacity to keep the client's business in an agency separate from its competitor. Clients may trust that the individual members of their agency will protect their information from leakage but within the limits of the agency's structural capacity to do so.

Given the relative importance of embedded exchange relationships to firms in professional services industries, the arguments were tested in the context of the advertising industry. Therefore, the generalizability of the study's findings may be limited to other service-based industries, such as investment banking, law and strategy consulting, which also are characterized by high ex ante uncertainty of the quality of services and the need to transfer sensitive information for the delivery of services (e.g. Nanda 2004). Furthermore, although change in control clauses were not an issue in the current study setting, they are common in other professional services such as law firms and would limit the applicability of the arguments developed here. Regardless, given the tremendous importance 
of the services sector to most major economies (e.g. 78.3 percent of GDP in the US in 2005 (Central Intelligence Agency 2006), this research clearly applies to a large percentage of firms. In addition, the reliance on longitudinal archival data necessitated the use of a proxy, relationship duration, for embeddedness. While this approach is consistent with prior research (e.g. Capaldo 2007, Gulati 1995, Seabright et al. 1992, Uzzi and Gillespie 2002), the use of more fine-grained measures of embeddedness in future research would aid in developing further insights into the conditions under which embeddedness increases the likelihood of relationship dissolution. Lastly, this study examined one instance of network dynamics that altered the effects of embeddedness on exchange - increases in competitive frictions among exchange partners of a firm post-merger. Future studies could investigate the effect of other network dynamics, for example changes to an exchange network when exchange partners make acquisitions or change their strategies, on the role of embeddedness in exchange.

This study offers several contributions. First, it extends research on the role competitive frictions play in exchange, and adds to a recent stream of studies that have begun to explore its effects on relationship dissolution (e.g. Greve et al. 2010, Rowley et al. 2005). Whereas past studies have focused on competitive overlap between a focal firm and its exchange partner, this study examines the implications of competitive overlap among a focal firm's exchange partners. This adds a new dynamic to the theory as it considers not only dyadic effects, but also network effects on dissolution.

Second, the study makes a contribution to research on the role of embeddedness in exchange by illustrating how its effects can change with the dynamics of the network. As shown here, the value of an embedded relationship for exchange stability is contingent upon the network in which the relationship is situated (cf. Gulati and Higgins 2003, Mizruchi et al. 2006). When the network changes, i.e. when competitive frictions among partners increase to high levels, embeddedness can increase the risk of relationship dissolution. For example, although embedded relationships provide a means for a firm to share fine-grained information with its partners, they may also lay the groundwork for the leakage of this information to other firms in an exchange network when competitive overlap is high.

Lastly, by providing an explanation for when tensions internal to embedded relationships lead to the dissolution of these relationships, this study suggests endogenous mechanisms for the 
dissolution of embedded relationships. To date, network research has primarily emphasized relationship formation, including the question of why potential partners choose to form- or not to form-relationships as an explanation for the evolution of network structures over time. However, existing theories do not provide adequate explanations for the dissolution of relationships once formed. As Marsden (1981: 1210) correctly noted, "Embeddedness refers to the fact that exchanges... typically have a history, and that this history results in the routinization and stabilization of linkages among members." The findings here suggest that although the effect of embeddedness on exchange is often a stabilizing one, ironically two key sources of stability - private information sharing and trust can become bases for future instability when competitive frictions among partners increase. 


\section{REFERENCES}

Ahuja, G. 2000. Collaboration networks, structural holes and innovation: A longitudinal study. Admin. Sci. Quart. 45(3) 425-455.

-----, G. Soda, A. Zaheer. 2012. The genesis and dynamics of organizational networks. Org. Sci. 23(2) 434-448.

Aiken, L. S. and S. G. West. 1999. Multiple Regression Testing and Interpreting Interactions. London Sage Publications.

Allison, P. D. 1982. Discrete-time methods for the analysis of event histories. Soc. Methodology 13 61-98.

-----. 1984. Event History Analysis Regression for Longitudinal Event Data. London, Sage Publications.

American Association of Advertising Agencies (AAAA). 1997. Industry report. www.aaaa.org.

Asker, J., A. Ljungqvist. 2010. Competition and the structure of vertical relationships in capital markets. $J$. Political Econ. 118(3) 599-647.

Bae, J., M. Gargiulo. 2004. Partner substitutability, alliance network structure, and firm profitability in the telecommunications industry. Acad. of Mgmt. J. 47(6) 843-859.

Baker, W. E. 1990. Market networks and corporate behavior. Amer. J. Soc. 96 (3) 589-625.

-----, R. R. Faulkner, G. A. Fisher. 1998. Hazards of the market: The continuity and dissolution of interorganizational market relationships. Amer. Soc. Rev. 63 147-177.

Baum, J. A. C., B. McEvily, T.J. Rowley. 2012. Better with age? Tie longevity and the performance implications of bridging and closure. Org. Sci. 23(2) 529-546.

-----, T.J. Rowley, A.V. Shipilov, Y.-T. Chuang. 2005. Dancing with strangers: Aspiration performance and the search for underwriting syndicate partners. Admin. Sci. Quart. 50(4): 536-575.

-----, J. V. Singh. 1994. Organizational niches and the dynamics of organizational mortality. Amer. J. Soc. 100(2) 346-80.

Beckman, C. M., P. R. Haunschild, D. J. Phillips. 2004. Friends or strangers? Firm-specific uncertainty, market uncertainty, and network partner selection. Organ. Sci. 15 (3) 259-275.

Bernheim, D., M. D. Whinston. 1990. Multimarket contact and collusive behavior. RAND J. Econom. 21 1-26.

Blau, P. M. 1964. Exchange and Power in Social Life. London, John Wiley \& Sons, Inc.

Breschi, S., F. Lissoni. 2001. Knowledge spillovers and local innovation systems: A critical survey. Indust. and Corp. Change 10 (4) 975-1005.

Broschak, J. P. 2004. Manager mobility and market interface: The effect of manager's career mobility on the dissolution of market ties. Admin. Sci. Quart. 49 (4) 608-640.

Buono, A. F., J. L. Bowditch. 1989. The Human Side of Mergers and Acquisitions. San Francisco Jossey-Bass.

Burt, R. S. 1992. Structural Holes. Cambridge, MA, Harvard University Press.

Capaldo. A. 2007. Network structure and innovation The leveraging of a dual network as a distinctive relational capability. Strat. Mgmt. J. 28 585-608.

Capron, L. 1999. The long-term performance of horizontal acquisitions. Strat. Mgmt. J. 20 (11) 987-1019.

Caves, R.E., M. Porter. 1977. From entry barriers to mobility barriers Conjectural decisions and contrived deterrence to new competition. Quart. J. Econom. 91 241-330.

Central Intelligence Agency (CIA). 2006. The World Fact Book. (http//www.cia.gov/cia/publications/factbook/index.html)

Chung, S., H. Singh, K. Lee. 2000. Complementarity, status similarity and social capital as drivers of alliance formation. Strat. Mgmt. J. 21(1)1-22.

Coleman, J. S. 1988. Social capital in the creation of human capital. Amer. J. Soc. 94 (Supplement) S95-S120.

----- 1994 (1990). Foundations of Social Theory. Cambridge, MA, Belknap Press. 
Comanor, W. S., A. J. Kover, R. H. Smiley.1981. Advertising and its consequences. In P. C. Nystrom and W. H. Starbuck (eds.), Handbook of Organ. Design, 2 429- 439. New York, Oxford University Press.

Cook, K. S., R. M Emerson, M. R. Gillmore, T. Yamagishi. 1983. The distribution of power in exchange networks: Theory and experimental results. Amer. J. Soc. 89 (2) 275-305.

Cox, D. R., D. Oakes. 1984. Analysis of Survival Data. London, Chapman and Hall.

Dirks, K. T., R.J. Lewicki, A. Zaheer. 2009. Repairing relationships within and between organizations: Building a conceptual foundation. Acad. of Mgmt. Rev. 34(1) 68-84.

Dore, R. 1983. Goodwill and the spirit of market capitalism. British J. Soc. 34 (4) 459-482.

Ducoffe, R. H., S. J. Smith. 1994. Mergers and acquisitions and the structure of the advertising agency industry. J. Current Issues \& Res. in Advertising 26 (Spring) 15-27.

Dyer, J. H., W. Chu. 2003. The role of trustworthiness in reducing transaction costs and improving performance: Empirical evidence from the United States, Japan and Korea. Org. Sci. 14(1) 57-68.

Eccles, R. G., D. B. Crane. 1988. Doing Deals Investment Banks at Work. Boston, MA, Harvard Business School Press.

Echols, A., W. Tsai. 2005. Niche and performance: The moderating role of network embeddedness., Strat. Mgmt. J. 26 219-238.

Emerson, R. M. 1962. Power-dependence relations. Amer. Soc. Rev. 27 (1) 31-41.

Farrelly, F., P. G. Quester. 2003. What drives renewal of sponsorship Principal/Agent relationships? J. Advertising Res. 43 (4) 353-360.

Flandin, M. P., E. Martin, L. P. Simkin. 1992. Advertising effectiveness research A survey of agencies, clients and conflicts. Internat. J. Advertising 11 (3) 203-214.

Gargiulo, M., M. Benassi. 1999. The dark side of social capital. In R. Leenders and S. M. Gabbay (eds.), Corporate Social Capital and Liability. London, Kluwer Academic Publishers, 298-322.

Geertz, C. 1978. The bazaar economy: Information and search in peasant marketing. Amer. Econom. Rev. 68 (2, Papers and Proceedings of the Ninetieth Annual Meeting of the Amer. Econom. Association) 28-32.

Gimeno, J. 2002. The performance effects of unintended and purposive multimarket contact. Managerial and Decision Econom. 23 209-224.

-----. 2004. Competition within and between networks: The contingent effect of competitive embeddedness on alliance formation. Acad. of Mgmt. J. 47 (6) 820-842.

-----, C. Y. Woo. 1996. Economic multiplexity The structural embeddedness of cooperation in multiple relations of interdependence. Adv. Strat. Mgmt. 13 323-361.

Gleason, M., P. Sloan. 1997. MIA on Madison Avenue Agency, client loyalty. Advertising Age, 68(4) 3-4

Gnyawali, D. R., R. Madhavan. 2001. Cooperative networks and competitive dynamics A structural embeddedness perspective. Acad. of Mgmt. Rev. 26 (3) 431-445.

Granovetter, M. 1985. Economic action and social structure: The problem of embeddedness. Amer. J. Soc. 91 (3) 481-510.

Greene, W. H. 1997. Econometric Analysis, $3^{\text {rd }}$ Edition. Upper Saddle River, NJ, Prentice Hall.

Greve, H. R. 2006. The intent and extent of multimarket contact. Strat. Organ. 4(3) 249-274.

-----, J. A. C. Baum, H. Mitsuhashi, T. J. Rowley. 2010. Built to last but falling apart: Cohesion, friction and withdrawal from interfirm alliances. Acad. of Mgmt. J. 53(2) 302-322.

Gulati, R. 1995. Does familiarity breed trust? The implications of repeated ties for contractual choice in alliances. Acad. of Mgmt. J. 38 (1) 85-112.

-----. 1998. Alliances and networks. Strat. Mgmt. J. 19(4), 293-317.

-----, M. Gargiulo. 1999. Where do interorganizational networks come from? Amer. J. Soc. 104 (5) 1439-1493.

-----, M. C. Higgins. 2003. Which ties matter when? The contingent effects of interorganizational partnerships on IPO success. Strat. Mgmt. J. 24 (2) 127-144. 
-----, M. Sytch. 2007. Dependence asymmetry and joint dependence in interorganizational relationships: Effects of embeddedness on a manufacturer's performance in procurement relationships. Admin. Sci. Quart. 52 32-69.

Gundlach, G.T. \& Cadotte, E.R. 1994. Exchange interdependence and interfirm interaction: research in a simulated channel setting. J. of Marketing Res. 31(4) 516-532.

Hambrick, D. C., A. A. Cannella. 1993. Relative standing: A framework for understanding departures of acquired executives. Acad. of Mgmt. J. 36 (4) 733-762

Hannan, M. T., J. Freeman. 1977. The population ecology of organizations. Amer. J. Soc. 82 929-964.

Hansen, M. T. 1999. The search-transfer problem: The role of weak ties in sharing knowledge across Organ. subunits. Admin. Sci. Quart. 44 (1) 82-111.

Harris, J., K.A. Taylor. 2003. The case for greater agency involvement in strategic partnerships. J. Advertising Res. 43 (4) 346-352.

Hayward, M. L. A., W. Boeker. 1998. Power and conflicts of interest in professional firms: Evidence from investment banking. Admin. Sci. Quart. 43 (1) 1-22.

Heckman, J. 1979. Sample selection bias as a specification error. Econometrica 47(1) 153-161.

Helgesen, T. 1994. Advertising awards and advertising agency performance criteria. J. Advertising Res. 34 (4) 43-53.

Hoetker, G. 2007. The use of logit and probit models in strategic management research critical issues. Strat. Mgmt. J. 28 331-343.

Hotz, M. R., J. K. Ryans Jr., W. L. Shanklin. 1982. Agency/client relationships as seen by influentials on both sides. J. Advertising 11 (1) 37-44.

Katz, M. L., C. Shapiro. 1985. Network externalities, competition, and compatibility. Amer. Econom. Rev. 75 (3) 424-440.

-----. 1986. Technology adoption in the presence of externalities. J. Political Econom. 94 (4) 822-841.

Kogut, B. 1989. The stability of joint ventures Reciprocity and competitive rivalry. J. Indust. Econom. 38 (2) 183-198.

Koka, B.R., R. Madhavan, J.E. Prescott. 2006. The evolution of interfirm networks: Environmental effects on patterns of network change. Acad. of Mgmt. Rev. 31721 - 737.

Korn, H. J., J. A. C. Baum. 1999. Chance, imitative, and strategic antecedents of multimarket contact. Acad. of Mgmt. J. 42 171-193.

Koza, M., A. Lewin. 1999. The coevolution of network alliances: A longitudinal analysis of an international professional service network. Org. Sci. 10(5) 638-653.

Krackhardt, D. 1987. QAP partialling as a test of spuriousness. Soc. Networks 9 171-186.

Krackhardt, D. 1988. Predicting with networks: A multiple regression approach to analyzing dyadic data. Soc. Networks 10 359-381.

Krug, J. A., R. V. Aguilera. 2005. Top management team turnover in mergers \& acquisitions. Adv. in Mergers and Acquisitions 4 123-151.

Larson, A. 1992. Network dyads in entrepreneurial settings: A study in the governance of exchange relationships. Admin. Sci. Quart. 37 76-104.

Lee, L.-F. 1983. Generalized econometric models with selectivity. Econometrica 51(2) 507-512.

Levinthal, D. A., M. Fichman. 1988. Dynamics of interorganizational attachments: Auditor-client relationships. Admin. Sci. Quart. 33 345-369.

Li, S. X., T. J. Rowley. 2002. Inertia and evaluation mechanisms in interorganizational partner selection: Syndicate formation among U.S. investment banks. Acad. of Mgmt. J. 45 (6) 1104-1119.

Liebowitz, S. J. and S. E. Margolis. 1994. Network externality: An uncommon tragedy. J. Econom. Perspectives 8 (2) 133-150. 
Madhavan, R., B. R. Koka., J. E. Prescott. 1998. Networks in transition: How industry events (re)shape interfirm relationships. Strat. Mgmt. J. 19 439-459.

Marsden, P. V. 1981. Introducing influence processes into a system of collective decisions. Amer. J. Soc. 86(6) 1203-1235.

McEvily, B. 2011. Reorganizing the boundaries of trust: From discrete alternatives to hybrid forms. Org. Sci. 22(5) 1266-1276.

-----, J. Jaffee, M. Tortoriello. 2012. Not all bridging ties are equal: Network imprinting and firm growth in the Nashville legal industry, 1933-1978. Org. Sci. 23(2) 547-563.

-----, A. Marcus. 2005. Embedded ties and the acquisition of competitive capabilities. Strat. Mgmt. J. 26 10331055.

-----, V. Perrone, A. Zaheer. 2003. Trust as an organizing principle. Org. Sci. 14(1) 91-103.

Michell, P. C. N., N. H. Sanders. 1995. Loyalty in agency-client relations: The impact of organizational context. J. Advertising Res. March/April 9-21.

Mizruchi, M. S., L. B. Stearns, C. Marquis. 2006. The conditional nature of embeddedness: A study of borrowing by large U.S. firms 1973-1994. Amer. Soc. Rev. 71 (2) 310-333.

Mulder, L.B., E. van Dijk, D. De Cremer, H.A.M. Wilke. 2006. Undermining trust and cooperation: The paradox of sanctioning systems in social dilemmas. J. of Exp. Soc. Psych. 42 147-162.

Nanda, A. 2004. Managing client conflict. Harvard Bus. School Res. Note, 9-904-059.

Oxley, J. E., R. C. Sampson. 2004. The scope and governance of alliances. Strat. Mgmt. J. 25 723-749.

Pagano, M., F. Panetta, L. Zingales. 1996. The stock market as a source of capital: Some lessons from initial public offerings in Italy. European Econom. Rev. 40 1057-1069.

----. 1998. Why do companies go public? An empirical analysis. J. Finance 53 27-64.

Park, S. H., M. V. Russo. 1996. When competition eclipses cooperation: An event history analysis of joint venture failure. Mgmt. Sci. 42 (6) 875-890.

Petersen, T.1985. A comment on presenting results from logit and probit models. Amer. Soc. Rev. 50 (1) 130131.

Piskorski, M. J., T. Casciaro. 2006. When more power makes actors worse off: Turning a profit in the American economy. Social Forces 85(2) 1011-1036.

Podolny, J. M. 1994. Market uncertainty and the social character of economic exchange. Admin. Sci. Quart. 39 458-483.

Polidoro, F., G Ahuja, W. Mitchell. 2011. When the social structure overshadows competitive incentives: The effects of network embeddedness on joint venture dissolution. Acad. of Mgmt. J. 54(1) 203-223.

Powell, W. W., White, D. R., Koput, K. W., J. Owen-Smith. 2005. Network dynamics and field evolution: The growth of interorganizational collaboration in the life sciences. Amer. J. Soc. 110 (4) 1132-1205.

Rabe-Hesketh, S., A. Skrondal. Multilevel and Longitudinal Modeling Using Stata. Stata Press, 2nd edition.

Reagans, R., B. McEvily. 2003. Network structure and knowledge transfer: The effects of cohesion and range. Admin. Sci. Quart. 48 240-267.

Reichheld, F. 1996. Learning from customer defections. Harvard Bus. Rev. 74 56-59.

Romer, P. 1987. Growth based on increasing returns due to specialization. Amer. Econom. Rev. 77 (2) 56-62.

Rowley, T. J., J. A. C. Baum. 2008. Introduction: Evolving webs in network economies. In J. A. C. Baum and T. J. Rowley (eds.), Network Strategy. Bingley, UK Emerald JAI.

-----, D. Behrens, D. Krackhardt. 2000. Redundant governance structures: An analysis of structural and relational embeddedness in the steel and semiconductor industries. Strat. Mgmt. J. 21 369-386.

-----, Greve, H. R., H. Rao, J.A.C. Baum, A.V. Shipilov. 2005. Time to break up: The social and instrumental antecedents of exit from interfirm exchange cliques. Acad. of Mgmt. J. 48: 499-520.

Seabright, M. A., D. A. Levinthal, M. Fichman. 1992. Role of individual attachments in the dissolution of interorganizational relationships. Acad. of Mgmt. J. 33 (1) 122-160. 
Shipilov, A. V. 2006. Network strategies and the performance of Canadian investment banks. Acad. of Mgmt. J. 49(3) 590-604.

-----, T. J. Rowley, B. Aharonson. 2006. When do networks matter? A study of tie formation and decay. Adv. in Strat. Mgmt. 23 481-519.

Singh, K., W. Mitchell. 1996. Precarious collaboration: Business survival after partners shut down or form new partnerships. Strat. Mgmt. J. 17 99-115.

Soda, G., A. Usai. 1999. The dark side of dense networks: From embeddedness to indebtedness. In A. Grandori (ed.), Interfirm Networks: Organizations and Industrial Competitiveness. London, Routledge, 276-302.

Somaya, D., I. O. Williamson, N. Lorinkova. 2008. Gone but not lost: The different performance impacts of employee mobility between cooperators and competitors. Acad. of Mgmt. J. 51 936-953.

Sorenson, O., D. M. Waguespack. 2006. Social structure and exchange: Self-confirming dynamics in Hollywood. Admin. Sci. Quart. 51 560-589.

Stark, D., B. Vedres. 2006. Social times of network spaces: Network sequences and foreign investment in Hungary. Amer. J. Soc. 111 (5) 1367-1411.

Sutherland, J., L. Duke, A. Abernethy. 2004. A model of marketing information flow. J. Advertising 33 (4) 39 52.

Uzzi, B. 1997. Social structure and competition in interfirm networks: The paradox of embeddedness. Admin. Sci. Quart. 42 35-67.

---- . 1999. Social relations and networks in the making of financial capital. Amer. Soc. Rev. 64 481-505.

-----, J. J. Gillespie. 2002. Knowledge spillover in corporate financing networks: Embeddedness and the firm's debt performance. Strat. Mgmt. J. 23 (7) 595-618.

-----, R. Lancaster. 2004. Embeddedness and price formation in the corporate law market. Amer. Soc. Rev. 69 (3) $319-344$.

Von Nordenflycht, A. 2007. Is public ownership bad for professional service firms? Ad agency ownership, performance and creativity, Acad. of Mgmt. J. 50(2) 429-445.

Walsh, J. P. 1988. Top management turnover following mergers and acquisitions. Strat. Mgmt. J. 9 (2) 173-183.

White, L. 2007. What long marriages mean to agencies. B\&T Magazine. August 10 14-17.]

Yamaguchi, K. 1996. Power in networks of substitutable and complementary exchange relations: A rationalchoice model and an analysis of power centralization. Am. Soc. Rev. 61 308-322. 
Table 1. Descriptive Statistics $(N=5899)$

\begin{tabular}{lrrrr}
\hline Variable & Mean & Std. Dev. & \multicolumn{1}{c}{ Min } & Max \\
\hline Client Relationship Dissolution & 0.17 & 0.37 & 0 & 1 \\
Relational Embeddedness & 4.19 & 2.75 & 1 & 21 \\
Difference in Competitive Overlap (Lagged) & 0.12 & 2.31 & -12 & 71 \\
Relationship Duration Truncated & 0.21 & 0.41 & 0 & 1 \\
Competitive Overlap Pre-Acquisition & 4.93 & 10.92 & 0 & 70 \\
Structural Embeddedness & 0.00 & 0.00 & 0 & 0.06 \\
Agency Dependence on Client & 0.05 & 0.06 & 0.01 & 1 \\
Client Size (Fortune Global 500) & 0.17 & 0.38 & 0 & 1 \\
Ln Client Industry Advertising Spend & 2.22 & 2.39 & 0 & 7.73 \\
Count of Client Industry Segments & 2.31 & 4.04 & 0 & 20 \\
Change in Ct. of Client Ind. Segments & 0.12 & 0.94 & -7 & 10 \\
Availability of Alternative Ad. Agencies & 4.19 & 1.63 & 0 & 6.80 \\
Count of Accounts Held by Ad Agency & 41.99 & 28.09 & 1 & 112 \\
Count of Accounts Lost by Ad Agency & 6.37 & 13.26 & 0 & 66 \\
Ln Agency Historical Comp. Overlap by SIC Code & 3.02 & 0.75 & 2.30 & 5.29 \\
Ln Agency Mean Historical Comp. Overlap & 4.06 & 1.16 & 0 & 6.66 \\
Count Agencies in Ad Firm & 21.00 & 9.75 & 1 & 39 \\
Ad Agency Employees & 645 & 4575 & 5 & 65000 \\
Proportion of Executive Departures & 0.23 & 0.27 & 0 & 1 \\
Award Winning Ad Agency & 0.38 & 0.48 & 0 & 1 \\
Ad. Agency Age (Years) & 37.23 & 28.40 & 1 & 150 \\
Target & 0.05 & 0.23 & 0 & 1 \\
\hline
\end{tabular}

Life Table

\begin{tabular}{rrrrrrrr}
\hline Interval & Total & Failures & Censored & $\begin{array}{c}\text { Cumulative } \\
\text { Failure }\end{array}$ & Error & \multicolumn{2}{c}{$\begin{array}{c}95 \% \\
\text { Confidence } \\
\text { Interval }\end{array}$} \\
\hline $2000-2001$ & 2167 & 469 & 40 & 0.782 & 0.009 & 0.764 & 0.798 \\
$2001-2002$ & 1658 & 231 & 60 & 0.671 & 0.010 & 0.650 & 0.690 \\
$2002-2003$ & 1367 & 158 & 86 & 0.591 & 0.011 & 0.569 & 0.611 \\
$2003-2004$ & 1123 & 198 & 925 & 0.414 & 0.013 & 0.388 & 0.439 \\
\hline
\end{tabular}


Table 2. Correlations $(\mathrm{N}=\mathbf{5 8 9 9})$

\begin{tabular}{|c|c|c|c|c|c|c|c|c|c|c|c|c|c|c|c|}
\hline & Variable & 1 & 2 & 3 & 4 & 5 & 6 & 7 & 8 & 9 & 10 & 11 & 12 & 13 & 14 \\
\hline 1. & Client Relationship Dissolution & & & & & & & & & & & & & & \\
\hline 2. & Relational Embeddedness & -.08 & & & & & & & & & & & & & \\
\hline 3. & Difference in Competitive Overlap (Lagged) & .02 & -.03 & & & & & & & & & & & & \\
\hline 4. & Relationship Duration Truncated & -.13 & .19 & -.02 & & & & & & & & & & & \\
\hline 5. & Competitive Overlap Pre-Acquisition & .00 & -.05 & -.01 & -.00 & & & & & & & & & & \\
\hline 6. & Structural Embeddedness & -.05 & -.05 & .02 & .07 & .29 & & & & & & & & & \\
\hline 7. & Agency Dependence on Client & -.06 & -.06 & .04 & .12 & .19 & .26 & & & & & & & & \\
\hline 8. & Client Size (Fortune Global 500) & -.05 & -.03 & .02 & .09 & .14 & .18 & .18 & & & & & & & \\
\hline 9. & Ln Client Industry Advertising Spend & -.03 & -.05 & .08 & .03 & .32 & .18 & .13 & .19 & & & & & & \\
\hline 10. & Count of Client Industry Segments & -.07 & .05 & -.00 & .08 & .08 & .11 & .22 & .28 & .05 & & & & & \\
\hline 11. & Change in Count of Client Ind. Segments & .02 & -.02 & .03 & -.01 & .09 & .06 & .04 & .12 & .03 & .32 & & & & \\
\hline 12. & Availability of Alternative Ad. Agencies & -.12 & .01 & .01 & .05 & .20 & .15 & .09 & .06 & .08 & .08 & .03 & & & \\
\hline 13. & Count of Accounts Held by Ad Agency & .05 & .05 & -.01 & -.13 & -.05 & -.06 & -.76 & -.14 & -.05 & -.09 & .00 & .01 & & \\
\hline 14. & Ln Count of Accounts Lost by Ad Agency & .58 & -.07 & .05 & -.19 & .04 & -.01 & -.17 & -.06 & -.03 & -.04 & .03 & -.15 & .19 & \\
\hline 15. & Ln Agency Historical Comp. Overlap by SIC Code & -.04 & .08 & .16 & .15 & .71 & .32 & .20 & .26 & .40 & .18 & .08 & .14 & -.01 & .01 \\
\hline 16. & Ln Agency Mean Historical Comp. Overlap & -.02 & .14 & .04 & .04 & .17 & -.01 & -.35 & -.01 & -.02 & -.02 & .02 & -.11 & .36 & .04 \\
\hline 17. & Count Agencies in Ad Firm & -.06 & .18 & .00 & .13 & .09 & -.09 & -.10 & -.00 & -.04 & .01 & .02 & .06 & .02 & -.07 \\
\hline 18. & Ln Ad Agency Employees & .01 & -.09 & -.02 & -.03 & .08 & .07 & -.14 & .05 & .08 & .10 & .05 & .25 & .25 & .11 \\
\hline 19. & Proportion of Executive Departures & .05 & -.03 & -.04 & -.00 & -.06 & -.02 & -.03 & .01 & -.00 & .04 & -.03 & .07 & .08 & .02 \\
\hline 20. & Award Winning Ad Agency & -.02 & -.04 & -.01 & .04 & -.03 & -.03 & .01 & -.02 & -.01 & .03 & .03 & -.07 & -.07 & .01 \\
\hline 21. & Ln Ad. Agency Age & .03 & .10 & -.02 & -.04 & -.03 & -.08 & -.19 & -.06 & -.06 & -.05 & .01 & -.03 & .02 & .06 \\
\hline 22. & Target & .04 & .05 & .19 & -.10 & -.10 & -.03 & .19 & -.04 & .05 & .03 & -.00 & .13 & -.18 & .03 \\
\hline
\end{tabular}

\begin{tabular}{llccccccc}
\hline & & $\mathbf{1 5}$ & $\mathbf{1 6}$ & $\mathbf{1 7}$ & $\mathbf{1 8}$ & $\mathbf{1 9}$ & $\mathbf{2 0}$ & $\mathbf{2 1}$ \\
\hline 16. & Ln Agency Mean Historical Comp. Overlap & .30 & & & & & & \\
17. & Count Agencies in Ad Firm & .26 & .67 & & & & & \\
18. & Ln Ad Agency Employees & .04 & -.06 & -.01 & & & & \\
19. & Proportion of Executive Departures & -.07 & -.17 & -.17 & .16 & & & \\
20. & Award Winning Ad Agency & .00 & -.01 & .20 & .21 & .00 & & \\
21. & Ln Ad. Agency Age & -.04 & -.05 & .08 & .17 & .03 & .23 & \\
22. & Target & -.04 & -.22 & -.08 & -.04 & .07 & -.01 & -.07 \\
\hline
\end{tabular}


Table 3. Likelihood of Client Relationship Dissolution: Discrete Time Complementary Log-Log Models

\begin{tabular}{|c|c|c|c|c|}
\hline & Model 1 & Model 2 & Model 3 & Model 4 \\
\hline Relational Embeddedness & $\begin{array}{l}-0.050 * * \\
(0.016)\end{array}$ & $\begin{array}{l}-0.057 * * * \\
(0.016)\end{array}$ & $\begin{array}{l}-0.064 * * * \\
(0.016)\end{array}$ & $\begin{array}{l}-0.067 * * * \\
(0.016)\end{array}$ \\
\hline Difference in Competitive Overlap (Lagged) & $\begin{array}{l}0.008 \\
(0.013)\end{array}$ & $\begin{array}{l}0.025 \\
(0.016)\end{array}$ & $\begin{array}{l}0.038^{*} \\
(0.015)\end{array}$ & $\begin{array}{l}0.049 * * \\
(0.016)\end{array}$ \\
\hline Rel. Embeddedness * Diff. in Comp. Overlap & & $\begin{array}{l}0.011^{*} \\
(0.005)\end{array}$ & $\begin{array}{l}0.015^{* *} \\
(0.005) \\
\end{array}$ & $\begin{array}{l}0.018^{* * *} \\
(0.005)\end{array}$ \\
\hline Relationship Duration Truncated & $\begin{array}{l}-0.259+ \\
(0.150)\end{array}$ & $\begin{array}{l}-0.271+ \\
(0.151)\end{array}$ & $\begin{array}{l}-0.230 \\
(0.165)\end{array}$ & $\begin{array}{l}-0.304+ \\
(0.171)\end{array}$ \\
\hline Competitive Overlap Pre-Acquisition & $\begin{array}{l}0.008 \\
(0.006)\end{array}$ & $\begin{array}{l}0.008 \\
(0.006)\end{array}$ & $\begin{array}{l}0.016^{*} \\
(0.007)\end{array}$ & $\begin{array}{l}0.017^{*} \\
(0.008)\end{array}$ \\
\hline Structural Embeddedness & $\begin{array}{l}-60.941^{*} \\
(24.109)\end{array}$ & $\begin{array}{l}-61.048^{*} \\
(24.205)\end{array}$ & $\begin{array}{l}-39.743 \\
(25.695)\end{array}$ & $\begin{array}{l}-35.131 \\
(26.023)\end{array}$ \\
\hline Agency Dependence on Client & $\begin{array}{l}0.115 \\
(0.111)\end{array}$ & $\begin{array}{l}0.109 \\
(0.111)\end{array}$ & $\begin{array}{l}0.101 \\
(0.113)\end{array}$ & $\begin{array}{l}0.100 \\
(0.120)\end{array}$ \\
\hline Client Size (Fortune Global 500) & $\begin{array}{l}-0.107 \\
(0.128)\end{array}$ & $\begin{array}{l}-0.105 \\
(0.128)\end{array}$ & $\begin{array}{l}-0.174 \\
(0.128)\end{array}$ & $\begin{array}{l}-0.273+ \\
(0.142)\end{array}$ \\
\hline Ln Client Industry Advertising Spend & $\begin{array}{l}0.006 \\
(0.020)\end{array}$ & $\begin{array}{l}0.005 \\
(0.020)\end{array}$ & $\begin{array}{l}0.003 \\
(0.019)\end{array}$ & $\begin{array}{l}0.011 \\
(0.026)\end{array}$ \\
\hline Count of Client Industry Segments & $\begin{array}{l}-0.043^{* * * *} \\
(0.013)\end{array}$ & $\begin{array}{l}-0.044 * * * \\
(0.013)\end{array}$ & $\begin{array}{l}-0.045^{* * *} \\
(0.013)\end{array}$ & $\begin{array}{l}-0.054^{* * *} \\
(0.014)\end{array}$ \\
\hline Change in Count of Client Ind. Segments & $\begin{array}{l}0.110^{*} \\
(0.048)\end{array}$ & $\begin{array}{l}0.110^{*} \\
(0.048)\end{array}$ & $\begin{array}{l}0.108^{*} \\
(0.047)\end{array}$ & $\begin{array}{l}0.113^{*} \\
(0.051)\end{array}$ \\
\hline Availability of Alternative Ad Agencies & $\begin{array}{l}0.045 \\
(0.031)\end{array}$ & $\begin{array}{l}0.043 \\
(0.031)\end{array}$ & $\begin{array}{l}0.720 * \\
(0.324)\end{array}$ & $\begin{array}{l}0.973 * * \\
(0.311)\end{array}$ \\
\hline Count of Accounts Held by Ad Agency & $\begin{array}{l}-0.037 * * * \\
(0.004)\end{array}$ & $\begin{array}{l}-0.037 * * * \\
(0.004)\end{array}$ & $\begin{array}{l}-0.036^{* * * *} \\
(0.008)\end{array}$ & $\begin{array}{l}-0.039 * * * \\
(0.008)\end{array}$ \\
\hline Ln Count of Accounts Lost by Ad Agency & $\begin{array}{l}1.636^{* * * *} \\
(0.054)\end{array}$ & $\begin{array}{l}1.634 * * * \\
(0.054)\end{array}$ & $\begin{array}{l}1.695^{* * *} \\
(0.090)\end{array}$ & $\begin{array}{l}1.727 * * * \\
(0.090)\end{array}$ \\
\hline Ln Agency Hist. Comp. Overlap by SIC Code & $\begin{array}{l}-0.169+ \\
(0.095)\end{array}$ & $\begin{array}{l}-0.174+ \\
(0.095)\end{array}$ & $\begin{array}{l}-0.271^{* *} \\
(0.099)\end{array}$ & $\begin{array}{l}-0.334^{* *} \\
(0.112)\end{array}$ \\
\hline Ln Agency Mean Historical Comp. Overlap & $\begin{array}{l}0.153+ \\
(0.081)\end{array}$ & $\begin{array}{l}0.159^{*} \\
(0.081)\end{array}$ & $\begin{array}{l}-0.104 \\
(0.166)\end{array}$ & $\begin{array}{l}-0.067 \\
(0.171)\end{array}$ \\
\hline Count of Agencies in Ad Firm & $\begin{array}{l}0.060 \\
(0.042)\end{array}$ & $\begin{array}{l}0.056 \\
(0.042)\end{array}$ & $\begin{array}{l}-0.032 \\
(0.044)\end{array}$ & $\begin{array}{l}-0.028 \\
(0.044)\end{array}$ \\
\hline Ln Ad Agency Employees & $\begin{array}{l}0.031 \\
(0.052)\end{array}$ & $\begin{array}{l}0.030 \\
(0.052)\end{array}$ & $\begin{array}{l}0.307 \\
(0.303)\end{array}$ & $\begin{array}{l}0.297 \\
(0.309)\end{array}$ \\
\hline Proportion of Executive Departures & $\begin{array}{l}0.434^{*} \\
(0.198)\end{array}$ & $\begin{array}{l}0.434^{*} \\
(0.199)\end{array}$ & $\begin{array}{l}0.353 \\
(0.368)\end{array}$ & $\begin{array}{l}0.372 \\
(0.363)\end{array}$ \\
\hline Award Winning Ad Agency & $\begin{array}{l}-0.026 \\
(0.092)\end{array}$ & $\begin{array}{l}-0.023 \\
(0.092)\end{array}$ & & \\
\hline Ln Ad Agency Age & $\begin{array}{l}0.006 \\
(0.067)\end{array}$ & $\begin{array}{l}0.000 \\
(0.067)\end{array}$ & & \\
\hline Target & $\begin{array}{l}0.194 \\
(0.183)\end{array}$ & $\begin{array}{l}0.171 \\
(0.184)\end{array}$ & & \\
\hline Selection Correction & $\begin{array}{l}-0.479 \\
(0.611)\end{array}$ & $\begin{array}{l}-0.516 \\
(0.603)\end{array}$ & $\begin{array}{l}-0.872 \\
(0.597)\end{array}$ & $\begin{array}{l}-1.066 \\
(0.690)\end{array}$ \\
\hline Acquisition Fixed Effects & Yes & Yes & No & No \\
\hline
\end{tabular}




\begin{tabular}{lcccc}
\hline & Model 1 & Model 2 & Model 3 & Model 4 \\
\hline Agency Fixed Effects & No & No & Yes & Yes \\
Client Industry Fixed Effects & No & No & No & Yes \\
\hline $\mathrm{N}$ & 5899 & 5899 & 4914 & 4879 \\
Log Pseudo-likelihood & -1504.79 & -1502.24 & -1516.42 & -1446.30 \\
Degrees of Freedom & 35 & 36 & 95 & 156 \\
in & $13.55^{* *}$ & $5.09^{*}$ & $133.96^{* * * *}$ & $107.81^{* * *}$ \\
\hline
\end{tabular}

$+\mathrm{p}<0.10, * \mathrm{p}<0.05, * * \mathrm{p}<0.01, * * * \mathrm{p}<0.001$

Robust standard errors in parentheses, clustered by parent company level dyad, Year fixed effects (4 groups) included in all models. In Model 3, 29 of 108 agencies dropped due to lack of variance in outcome, 8 agency dummies were omitted due to collinearity. In Model 4, 7 of 75 industries dropped due to lack of variance in outcome, 7 industry dummies were omitted due to collinearity. For log likelihood ratio tests, the comparison model for Model 1 is the model including only control variables (not reported here), and for Model 2 it is Model 1. For Model 3, comparison is with same model omitting ad agency fixed effects. For Model 4, comparison is with same model omitting client industry effects. 


\section{Figure 1. Competitive Overlap Following an Acquisition*}
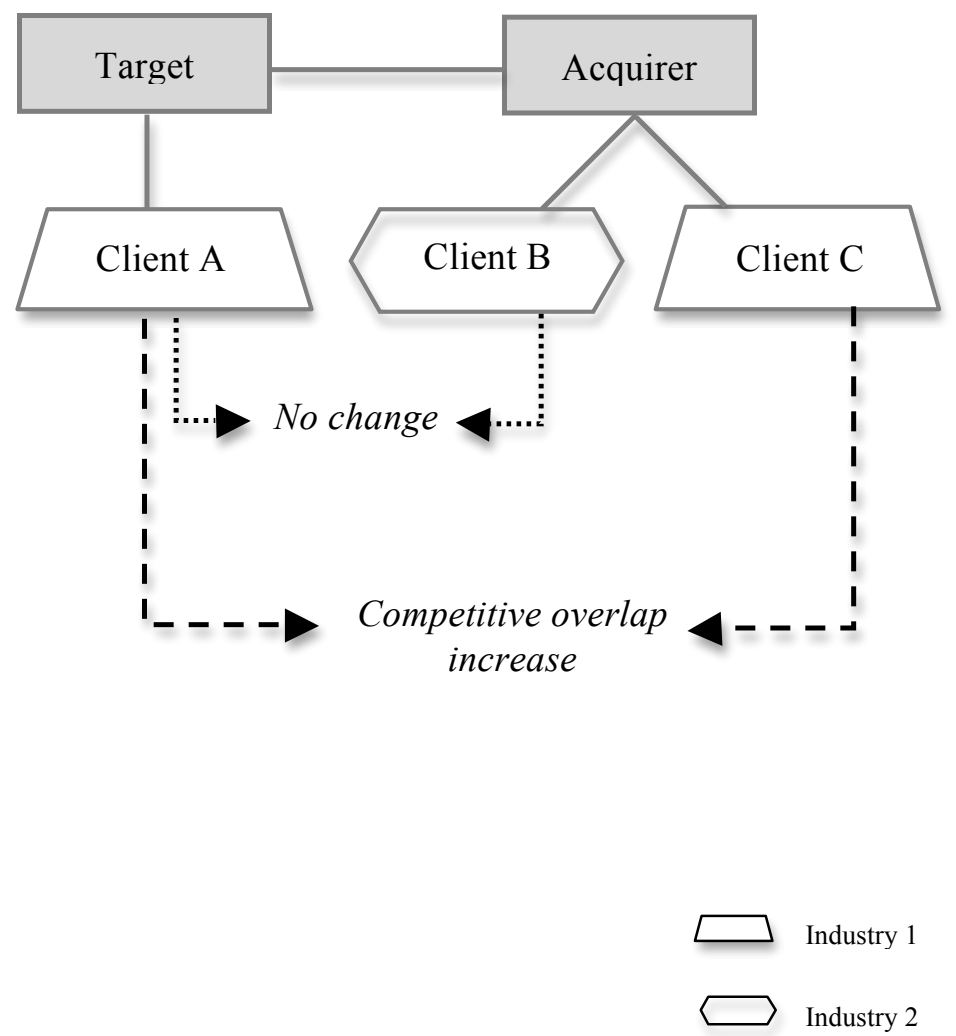

* Figure 1 illustrates the increase in competitive overlap that occurs as a result of an acquisition or merger for Client $\mathrm{A}$ and Client $\mathrm{C}$ who compete in the same industry. Client $\mathrm{B}$ which competes in a different industry does not experience an increase in competitive overlap. 
Figure 2. Conditional Probability of Relationship Dissolution*

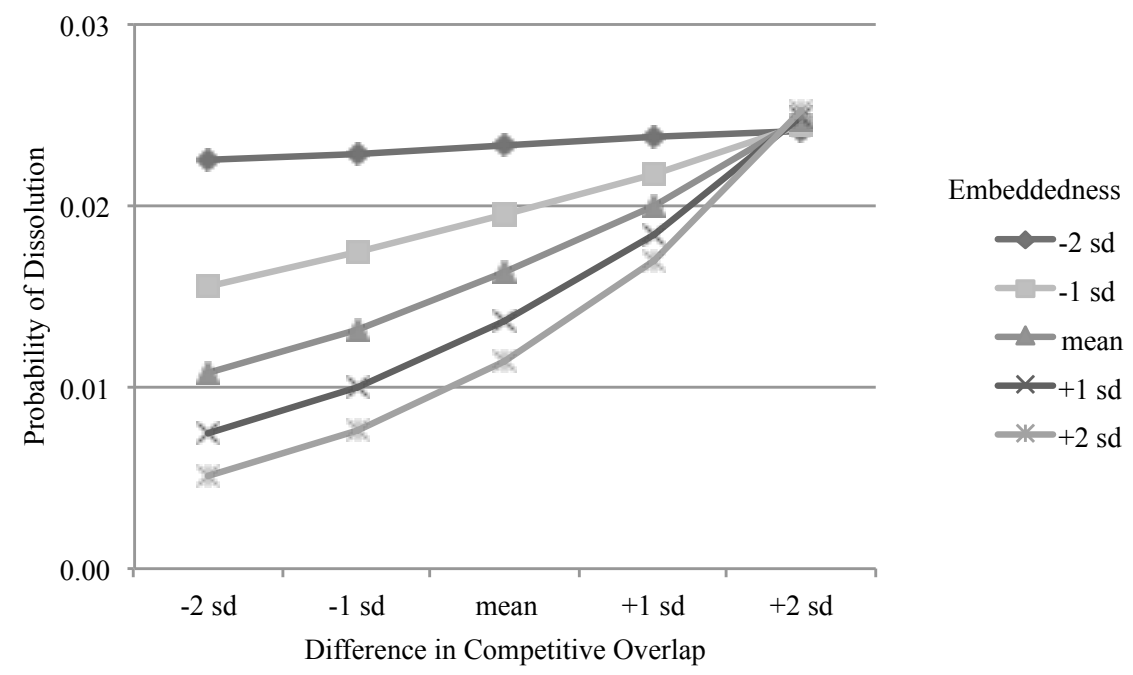

* Graph is based on conditional probabilities calculated using the estimates in Model 4 in Table 3 which include agency and client industry fixed effects. All variables held at their means except the interacted variables, relational embeddedness and difference in competitive overlap. 


\section{Figure 3. Conditional Probability of Relationship Dissolution:} Low, Mean and High Counts of Agencies in Advertising Firm
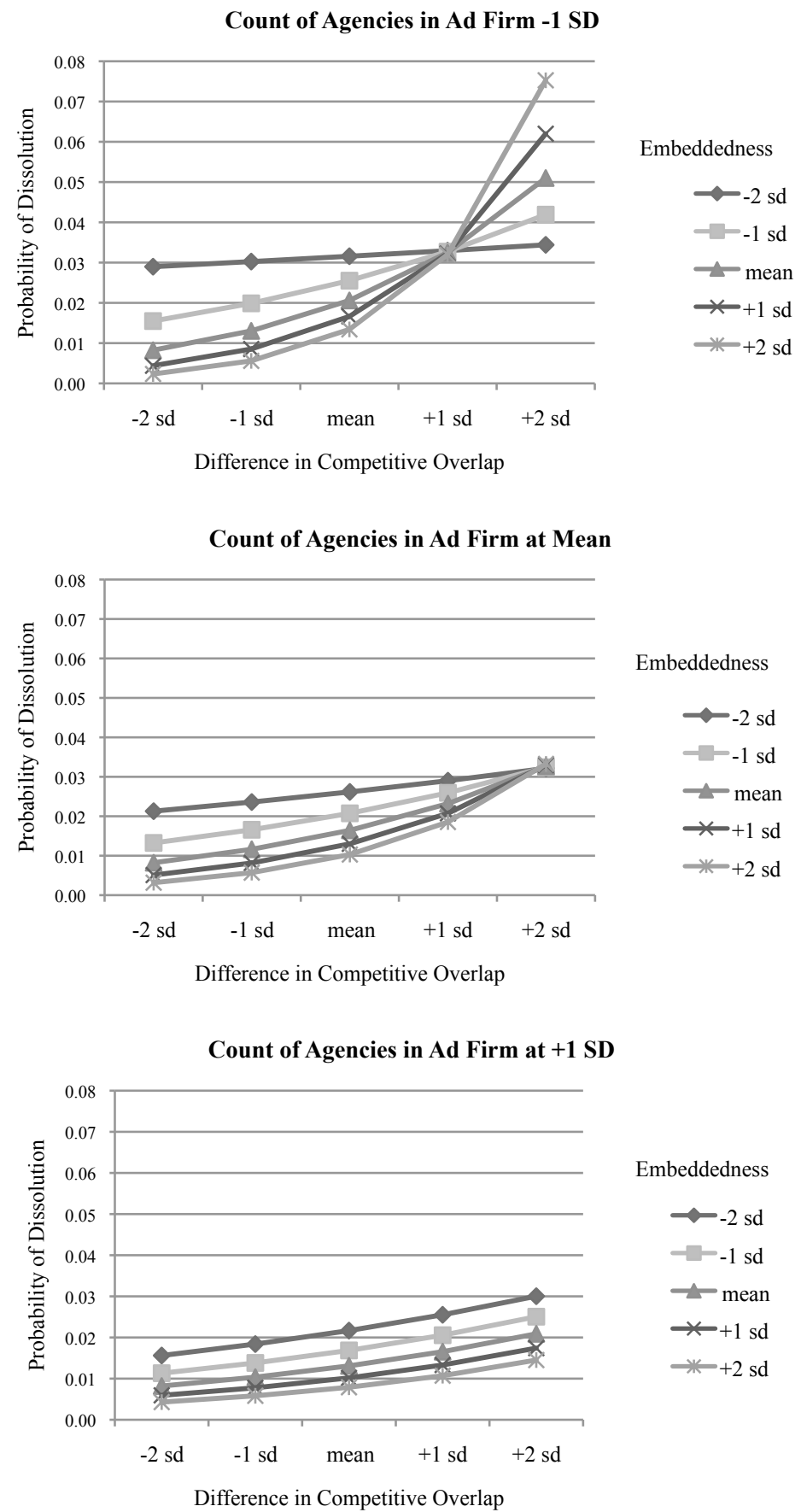

* Graphs are based on conditional probabilities calculated using the estimates from models including the 3way interaction of relational embeddedness, difference in competitive overlap and the count of agencies in the advertising firm. All variables held at their means except the interacted variables, relational embeddedness, difference in competitive overlap and count of agencies in ad firm. 